\title{
Contrast effects as a function of shifts in delay of water reward
}

\author{
HUGH J. FERRELL and MITRI E. SHANAB \\ California State University, Fresno, California 93710
}

\begin{abstract}
Following stable performance in the acquisition (preshift) phase, subjects receiving either 0 , 8 , or $16 \mathrm{sec}$ delay of water reward were subdivided and either continued on the preshift delay, or shifted to the other preshift delay intervals. The postshift performance was examined for evidence of positive and negative contrast effects. It was found that delay produced significant differences in acquisition such that, the shorter the delay interval, the faster the running speed. This effect was also found in the second phase in which the same relationship held between length of delay and speed, regardless of earlier acquisition experience. Although a graphical, albeit statistically nonsignificant, PCE was observed in all sections of the runway, no NCE was found. The results were discussed in terms of several theories of behavior.
\end{abstract}

A substantial number of studies have been reported in recent years investigating the phenomena associated with contrasted conditions of reinforcement. When subjects in an instrumental learning situation are shifted from small to large reward and exceed the performance level of subjects maintained on large reward all the time, a successive positive contrast effect (PCE) is said to have occurred. A successive negative contrast (NCE) effect occurs when subjects shifted from large to small reward perform at a significantly lower level than subjects maintained on small reward all the time.

According to recent reviews (Dunhan, 1968), successive NCE has emerged as a fairly reliable finding in the runway. Positive contrast, however, has been much more difficult to obtain in the runway, but has recently been found when shifts in reward magnitude are introduced along with delay (Mellgren, 1972; Shanab \& Biler, 1972; Shanab, Sanders, \& Premack, 1969). This procedure was used to control for any ceiling effects associated with the running response (Bower, 1961).

Studies which have employed shifts in delay of reward in nonrunway situations have generally shown an absence of either positive or negative contrast (Harker, 1956; Logan, 1952; Sgro, Glotfelty, \& Moore, 1970). Shanab and McCuistion (1970) and Shanab and Biller (1972), using a straight runway, found a NCE with a shift from 0 to $15 \mathrm{sec}$ delay. Similarly, McHose and Tauber (1972) found an immediate and significant NCE in the runway with a shift from 10 to 30 sec delay. On the other hand, using the runway Shanab (1971) and Shanab and Cavallaro (1973) found a graphical, but nonsignificant, NCE in subjects shifted from 0 - to 15 -sec delay. Mackintosh and Lord (1973) also found no evidence of a successive NCE in the runway based on

This paper is based in part on the first author's master thesis. Hugh J. Ferrell is now at Purdue University, West Lafayette, Indiana, 47907

Requests for reprints should be sent to Mitri E. Shanab, Department of Psychology, California State University, Fresno, California, 93740. shifts from 0 - to 15 -sec delay, although a similar shift in a simultaneous paradigm produced a significanct NCE. Shanab, Rouse, and Cavallaro (1973) found neither PCE nor NCE based on shifts in delay $(0 \mathrm{sec}$ and $30 \mathrm{sec})$ intervals as a function of magnitude of reward (1 or 22 pellets). Recently, Shanab and Cavallaro (1975) found no PCE based on a shift from a $30-\mathrm{sec}$ to a $10-\mathrm{sec}$ delay interval. The latter two studies also used the runway.

In all of the preceding studies food in solid form was the reinforcer. There is perhaps only one study which studied PCE using water reinforcement. Using the runway, Sgro and Weinstock (1963) shifted thirsty rats from 15 and 7.5 -sec delay to immediate reward: the reward consisted of $20-\mathrm{sec}$ access to a drinking tube. Significant PCE was reported for the subjects shifted from $15 \mathrm{sec}$ to immediate reward. Logan and Spanier (1970) found that delay of food reward interacted with delay of water reward such that under short delay (1 sec) food-deprived subjects ran faster than water-deprived subjects, but the reverse was true under long delay $(30 \mathrm{sec})$. This finding has important implications for contrast studies in that it suggests that thirsty rats would not run close to their upper or lower limit. The use of water deprivation would thus, provide a means of controlling for the ceiling effect as well as any possible floor effect associated with the running response (cf. Shanab et al., 1973).

\section{METHOD}

\section{Design}

The experiment consisted of two phases. A design of three randomized groups was used in Phase 1 , in which 21 subjects were assigned to each of three delay conditions: 0,8 , and $16 \mathrm{sec}$. In Phase 2, each main group was subdivided into three equal subgroups, resulting in nine groups with seven subjects per group, according to a 3 by 3 factorial design. One subgroup continued to receive the same delay interval as before, while the other two subgroups were shifted to the other two delay intervals. Thus, the following nine groups were run in Phase 2: $0-0,0-8,0-16,8-0,8-8,8-16,16-0,16-8,16-16$. The number 


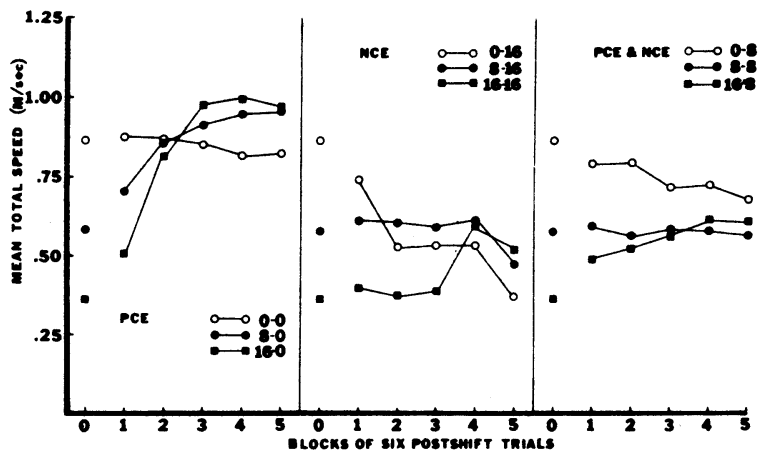

Figure 1. Mean total speed as a function of shifts in delay of water reward.

preceding the hyphen represents Phase 1 conditions, while the second number represents Phase 2 conditions.

\section{Subjects}

The subjects were 63 naive male albino rats of the Sprague-Dawley strain, about 90 days old at the start of the experiment.

\section{Apparatus}

A 1.5-m runway of unpainted redwood was used. The runway was the same as that described ealier (Shanab \& Cavallaro, 1975).

Within the goalbox, however, a small metal plate $(2.5 \mathrm{~cm}$ square) was fixed to the far wall of the goalbox, and surrounded an aperture located $4.2 \mathrm{~cm}$ from the goalbox floor. Through this aperture, a drinking tube was presented automatically to the subject after the appropriate delay interval, and then retracted after the prescribed access interval had elapsed. During the delay interval, the subject was confined to the goalbox by means of the second guillotine door which separated that region from the run section.

\section{Procedure}

Upon arrival from the supplier, the subjects were housed in individual cages and were handled daily for 2-3 min for a total of 18 days. Following this handling stage, the subjects were placed on a $231 / 2-h$ deprivation schedule. After a total of 12 days on the deprivation schedule, subjects were given exploration in the runway. No water was provided in the runway during exploration. On the first day, each subject was given 90-sec exploration with all guillotine doors open and all equipment turned off. On the second and third days, subjects were again given 90-sec exploration of the runway with doors operated in the same fashion as on regular trials, and all equipment turned on to accustom the subjects to the sounds of the equipment. Following this, 2 days of operant levels were taken. After randomly assigning subjects to the three conditions, Phase 1 was started. This phase lasted 17 days. On the first two days of Phase 1, each subject received one trial a day, but thereafter each subject received two trials per day. For all subjects in both phases the reinforcer consisted of $16 \mathrm{sec}$ access to the drinking tube. The delay interval started when a subject broke the last photobeam located within the goalbox. The subjects were run in groups of six with an intertrial interval (ITI) of 6-7 min. Each subject received its daily ration of water $25-30 \mathrm{~min}$ following its second daily trial, in both phases.

In Phase 2, subjects were matched on the basis of asymptotic performance levels in Phase 1 and divided into three subgroups as described previously. Duration of access to the drinking tube was not changed. As in Phase 1, subjects were run in groups of six with a 6-7 min ITI. Phase 2 was continued for 15 days at two trials per day. In both phases, the subjects had free access to food.

\section{RESULTS}

All analyses are based on total speed measures $(\mathrm{m} / \mathrm{sec})$ since all other speed measures were similar.

\section{Phase 1}

Although Figure 1 shows the mean total running speed $(\mathrm{m} / \mathrm{sec})$ as a function of six trial blocks, all statistical tests using the blocks factor were based on two-trial blocks. Two separate analyses of variance with repeated measures were performed over the last six and the last three blocks yielding slightly similar results. Because of this similarity in results, only the analysis of the last three blocks will be reported. The delay effect was significant $[F(2,60)=20.65, p<.001]$, but the blocks effect was not, $F<1$. No Delay by Blocks interaction effect was obtained, $\mathrm{F}<1$.

Individual comparisons showed that Group 0 ran significantly faster than Group $16[F(1,60)=42.28$, $\mathrm{p}<.001]$, as well as Group $8[\mathrm{~F}(1,60)=10.15$, $\mathrm{p}<.005]$. Group 8 ran significantly faster than Group $16[F(1,60)=10.50, p<.005]$.

\section{Phase 2}

Separate three-way analysis of variance tests using Phase 1 and Phase 2 delay conditions as the two between-subjects factors and the last four (eight trials) or eight blocks (16 trials) as the third (within-subjects) factor yielded highly similar results. Only the results of the analysis of the last four blocks will be reported. No significant Phase 1 treatment (delay) effect was found $\mathrm{F}<1$. In contrast, Phase 2 conditions produced highly significant effects $[F(2,54)=15.04, p<.01]$. Thus, performance was clearly a function of the prevailing conditions of delay of reward in both phases. No significant interaction effect between Phase 1 and Phase 2 delay conditions was found, $\mathrm{F}<1$. However, the blocks effect was significant $[F(3,162)=5.28$, $\mathrm{p}<.01]$. None of the interaction effects with blocks was significant. Separate graphs were drawn for each of the four measures in terms of each trial as well as blocks of two trials. No clear indication of NCE was observed, but an apparent PCE was observed in all cases. Appropriate pairwise comparisons for PCE using the Newman-Keuls test was performed over the last four blocks (eight trials) yielding nonsignificant results $(p>.05)$, thus disconfirming the graphical PCE. Similarly, the Newman-Keuls test revealed no significant NCE ( $p>.05)$. for all possible comparisons. The only significant pairwise comparisons obtained were those that supported the significant Phase 2 delay effect revealed by the analysis of variance test. 


\section{DISCUSSION}

The results of the present study provide strong evidence for the effects of constant delay of water reinforcement on runway performance. First, a clear demonstration was made of the effect of constant delay on asymptotic acquisition performance in all sections of the runway. The longer the delay interval, the slower the running speed. The stability of this finding is reflected in the lack of any significant changes in total speed over the last 12 and the last 6 trials of the acquisition phase. This finding supports two other studies in which water reinforcement was also used (Sgro, Dyal, \& Anastasio, 1967; Sgro \& Weinstock, 1963).

Further support for the acquisition delay effect is to be found in a study which manipulated both sucrose concentration and delay interval in a barpress situation (McCloskey \& Tombaugh, 1971). Significant delay effects in acquisition have been reported in a number of studies using food reward (Logan, 1960; Mackintosh \& Lord, 1973; Shanab \& Biller, 1972; Shanab \& McCuistion, 1970). Thus, the results of the present study in Phase 1 are congruent with other findings of the effects of food and sucrose delay upon performance, and lend further support to the slender evidence of these effects when water reinforcement is delayed.

A second interesting finding in Phase 1 refers to the slow acquisition curves of the delayed groups. In particular, the subjects that received a 16-sec delay did not appear to show any significant improvement in performance during the acquisition phase. The performance of this group remained essentially at its operant level. This is in agreement with the results of several studies in which food reward was used (cf. Campbell \& Knouse, 1972).

Several interesting findings were obtained during the shift phase (Phase 2). As in the acquisition phase, significant delay effects were also present in the shift phase. Thus, slower running resulted from longer delay with no interaction between Phase 1 and Phase 2 conditions. A graphical but statistically nonsignificant, positive contrast effect was observed for both Groups 8 and 16 shifted to immediate reward. This finding agrees, in part, with that of Sgro and Weinstock (1963) who found significant PCE only for subjects shifted from $15 \mathrm{sec}$ to $0 \mathrm{sec}$ delay. As in the study by Sgro et al. (1967), Sgro and Weinstock (1963) eliminated the 15 slowest subjects prior to the acquisition phase of their experiment, thus biasing their sample in favor of faster running subjects. Thus, it is not possible to attribute the PCE obtained to either the shift in delay or to the particular selection procedure used.

Although the graphical positive contrast effect was observed in all segments of the runway, it did not approach statistical significance in any measure. This finding is in accord with the large number of food-reward studies which have found no evidence for PCE in the runway based on shifts in magnitude or delay (Shanab \& Biller, 1972; Shanab \& Cavallaro, 1975; Shanab, Rouse \& Cavallaro, 1973). The lack of a statistical PCE in this study is puzzling, and calls for further investigation of this phenomenon using various delay intervals.

The absence of negative contrast in the present study is in agreement with a number of food-reward studies which have been unable to produce negative contrast based on shifts in delay in a successive design (Mackintosh \& Lord, 1973; Shanab, 1971; Shanab \& Cavallaro, 1973; Shanab, et al., 1973). The absence of NCE based on shifts in delay supports other nonrunway studies (Logan, 1952; Harker, 1956). Only McHose and Tauber (1972) have reported finding a successive NCE in the runway based on a shift from 10 to $30-\mathrm{sec}$ delay. It is interesting to note that, although NCE is reliably obtained when shifts in magnitude of food reward are made, a corresponding effect based on shifts in either concentration or magnitude of sucrose reward has not been found (Flaherty, Riley, \& Spear, 1973).

According to frustration theory (Surridge, Mock, \& Amsel, 1968), subjects receiving constant delay in acquisition do not experience frustration because they never form an expectation of immediate reward. However, frustration theory, it would seem, should predict negative contrast for subjects shifted from immediate reward to some delay since the shifted subjects would have already formed an expectation of immediate reward and should experience frustration when confronted with delayed reward. This, in turn, would be reflected in avoidance responses that interfere with the ongoing learned response. Within the present formulation of frustration theory, it is conceivable to predict no NCE based o shifts in delay. It might be argued that although a shift from no delay to some delay or from some delay to longer delay, might produce frustration, the receipt of the reinforcer in full after 'each delay interval might attenuate the emotional frustrative effects, thus accounting for the absence of NCE.

Sequential theory (Capaldi, 1967) has more specific predictions concerning the effects of delay. Capaldi made the assumption that longer delays support less habit strength than shorter delays, which would account for the reliable delay acquisition effects in this and other studies. While the sequential theory predicts no PCE but a reliable NCE when shifts are made in magnitude of reward, it predicts neither PCE nor NCE based on shifts in delay of reward. The latter prediction concerning NCE is inevitable if it is recognized that no change takes place in the stimulus intensity factor (V) because the reward magnitude does not change throughout training.

The present results pose difficulties for any theory that emphasizes the relative effects of reinforcement conditions. According to adaptation-level theory (Helson, 1964), both PCE and NCE should have been observed. Granting that the graphical PCE could conceivably reflect a genuine effect, the adaptation-level theory still must deal with the absence of NCE in this study.

It seems clear that more empirical work should be carried out based on shifts in water reward before any theoretical attempt can be made to explain contrast effects with water rewards.

\section{REFERENCES}

Bower, G. H. A contrast effect in differential conditioning. Journal of Experimental Psychology, 1961, 62, 196-199.

Campbell, P. E., \& Knouse, S. B. Extinction following delayed reward: A review. Psychonomic Monograph Supplements, 1972, 4, 257-268.

Capaldi, E. J. A sequential hypothesis of instrumental learning. In K. W. Spence and J. T. Spence (Eds.) The psychology of learning and motivation. Vol. 1, New York: Academic Press, 1967, Pp. 67-156.

Dunham, $P$. J. Contrasted conditions of reinforcement: A selective critique. Psychological Bulletin, 1968, 69, 295-315.

Flaherty, C. F., Riley, E. P., \& Spear, N. E. Effects of sucrose concentration and goal units on runway behavior in the rat. Leaming and Motivation, 1973, 4, 163-175.

Harker, G. S. Delay of reward and performance of an instrumental response. Journal of Experimental Psychology, 1956, 51, 303-310.

Helson, H. Adaptation-level theory: An experimental and systematic approach to behavior. New York: Harper \& Row, 1964.

Logan, F. A. The role of delay of reinforcement in determining reaction potential. Journal of Experimental Psy chology, 1952 43, 393-399.

Logan, F. A. Incentive. New Haven: Yale University Press, 1960.

Logan, F. A., \& Spanier, D. Relative effects of delay of food and water reward. Journal of Comparative and Physiological Psychology, 1970, 72, 102-104.

Mackintosh, N. J., \& Lord, J. Simultaneous and successive contrast with delay of reward. Animal Learning \& Behavior,

McCloskey, J. L., \& Tombaugh, T. N. Sucrose concentration. constant delay of reward, and resistance to extinction. Journal of Experimental Psy chology, 1971, 88, 128-132.

McHose, J. H., \& Tauber, L. Changes in delay of reinforcement in simple instrumental conditioning. Psy chonomic Science, 1972, 27, 291-292.

Mellgren, R. L. Positive and negative contrast effects using delayed reinforcement. Learning and Motivation, 1972, 3,

Sgro, J. A., Dyal, J. A., \& Anastasio, E. J. Effects of constant 
delay of reinforcement on acquisition asymptote and resistance to extinction. Journal of Experimental Psychology, $1967,73,634-636$.

Sgro, J. A., Glotfelty, R. A., \& Moore, B. D. Delay of reward in the double alleyway: A within-subjects vs. between-subjects comparison, Journal of Experimental Psychology, 1970, 84, 82-87.

Sgro, J. A., \& Weinstock, S. Effects of delay on subsequent running under immediate reinforcement. Journal of Experimental Psychology, 1963, 66, 260-263.

Shanab, M. E. Positive transfer between nonreward and delay. Journal of Experimental Psychology, 1971, 91, 98-102.

Shanab, M. E., \& Biller, J. D. Positive contrast in the runway obtained following a shift in both delay and magnitude of reward. Learning \& Motivation, 1972, 3, 179-184.

Shanab, M. E., \& Cavallaro, G. Transfer between nonreward and delay of reward following minimal acquisition training. Animal Learning \& Behavior, 1973, 1, 179-182.
Shanab, M. E. \& Cavallaro, G. Positive contrast obtained with a shift in magnitude, delay, and schedule of reward. Bulletin of the Psy chonomic Society, 1975, in press.

Shanab, M. E., \& McCuistion, S. Effects of shifts in magnitude and delay of reward upon runway performance in the rat. Psy chonomic Science, 1970, 21, 264-266.

Shanab, M. E., Rouse, L. O., \& Cavallaro, G. Effects of shifts in delay of reward in rats as a functon of reward magnitude. Journal of General Psy chology, 1973, 89, 59-66.

Shanab, M. E., Sanders, R., \& Premack, D. Positive contrast in the runway obtrained with delay of reward. Science, 1969. 164, 724-725.

Surridge, C. T., Mock, K. R., \& Amsel, A. Effect on interpolated extinction after partial delay or reward training on subsequent reqcquistion and extinction. Quarterly Journal of Experimental Psy chology, 1968, 20, 321-328.

(Received for publication January 17, 1975.) 